\title{
SYMBIONT: FLORA AND FAUNA AS INHABITANTS OF ARCHITECTURE
}

\author{
ADRIÁN CEBRIÀ \\ Veritas University, Costa Rica
}

\begin{abstract}
When discussing the role of nature in architecture, reference is often made either to its uses in solving energy consumption problems, or to its formal and functional repertoire for architectural design. However, the rapidly expanding built environment is replacing the natural environment; dwelling places supposedly reserved for biodiversity within the city, are disappearing - along with the presence of vegetation - which leads to a negative impact on the quality of human life. The present paper aims to bring to the table a discussion as to how to consider flora and fauna as inhabitants of architecture at the building scale, and to approach a conversation where these two elements - flora and fauna - are more than a utility, without any intention of anthropomorphizing them, where human beings and nature are equal partners, without a dominance of one as opposed to the other. At the same time, this paper focuses on the effects on the quality of life of the human being when entering into a relationship of such nature. With this idea in mind, a habitation typology named "Symbiotic Space" is proposed in the hope that it will serve as a habitation model for vegetation in architecture.
\end{abstract}

Keywords: architecture, biodiversity, dwelling, flora, fauna, symbiosis, sustainability, typology.

\section{INTRODUCTION}

Much of the built environment today is so sensory deprived that certain authors, such as Wilson, according to Beatley [1], have reflected on whether the global loss of biodiversity impoverishes the human species and whether we are creating the conditions for a solitary existence.

Hard-surfaced, arid, and grey urban environments may often feel lonely because of the absence of animals and other non-human forms of life. The loss of biodiversity within the cities, in addition to the evident negative impact it has on the environment and ecosystems, such as the loss of pollinators, also pauperizes the human dwelling from a quality of life point of view. We need these "others" forms of life to complement us, to defend us from loneliness. As Kellert and Calabrese [2] analyze about Heerwagen: much of the built environment today is so sensory deprived that it sometimes reminds one of the sterile cages of the old-fashioned zoo, now ironically banned as "inhuman". Just like Stephen Kellert points out, as cited by Beatley [1], these are unusual times when we have to defend and rationalize our need for contact with nature.

Although the criteria of energy sustainability is part of the fundamental principle of "green" architecture. To consider the flora and fauna as inhabitants of architecture, for the purpose of this paper, it's the result of a vision that places the concept of biodiversity before that of sustainability. Despite the arguments related to human welfare conservation and production of renewable energy or energy-efficient building systems being undoubtedly essential issues when talking about the role of nature in architecture, the approach to the concept of biodiversity is based on the idea that humanity is only one of many presences on the planet and that is why new forms of coexistence must be found [3].

Nature should not be an afterthought or be seen only in terms of the functional benefits (considerable as they are) it provides [1]. If vegetation is only appreciated for its energetic or biophilic value, then it is no more than a utility, no different from a piece of furniture, an 
ornament, a wall, or a solar panel; and therefore, it would not be considered as another inhabitant of architecture.

\section{THE "NEW" TENANTS}

Many architects consider architecture as a space with the function of fulfilling certain standards of comfort for the human being, estimating that it is the latter the only one who dwells in these spaces. This definition has its logic if we consider that throughout history, architectural design has adopted solutions for the survival of human beings. However, we cannot forget the strong connection between human beings and nature throughout history, and the need to coexist with it since the beginning of civilization, as was the case, for example, of the Hanging Gardens of Babylon.

Different authors describe the palace as high stone terraces imitating mountains and hanging gardens [4]. While it is true that the existence of the Hanging Gardens of Babylon is lost in the mists of history, and academics and historians still debate its existence, the fact remains that the concept of a building covered with vegetation has been considered, for thousands of years, as an ideal construction. So much so that the Hanging Gardens of Babylon are admired as one of the Seven Wonders of the Ancient World.

However, at some point in history, this innate affinity that human beings had for living with nature is lost and is replaced by the desire to inhabit a hermetic interior space, with controlled air conditioning, to such an extent that this new habitat is accepted as an indicator of ideal comfort, where the notion prevails that a more sustainable model, which might also interact with nature, is the equivalent of returning to a medieval era, without comfort for human beings [5].

This "hermetic sealing", together with an emotional disidentification and an increase in the price of urban land, have led to the extermination of trees in patios and pavements in order to save on vegetation maintenance work [6].

In Costa Rica, for example, biodiversity in the greater metropolitan area is often found on riverbanks, in public parks, in private gardens, or on sidewalks [6]. However, there has been a loss of biodiversity, and in these places, where biodiversity is supposed to be found, plants and trees have gradually been exterminated and replaced with aesthetic solutions without environmental criteria; the existing vegetation has been replaced with sterile and decorative materials such as synthetic grass or concrete (Fig. 1).

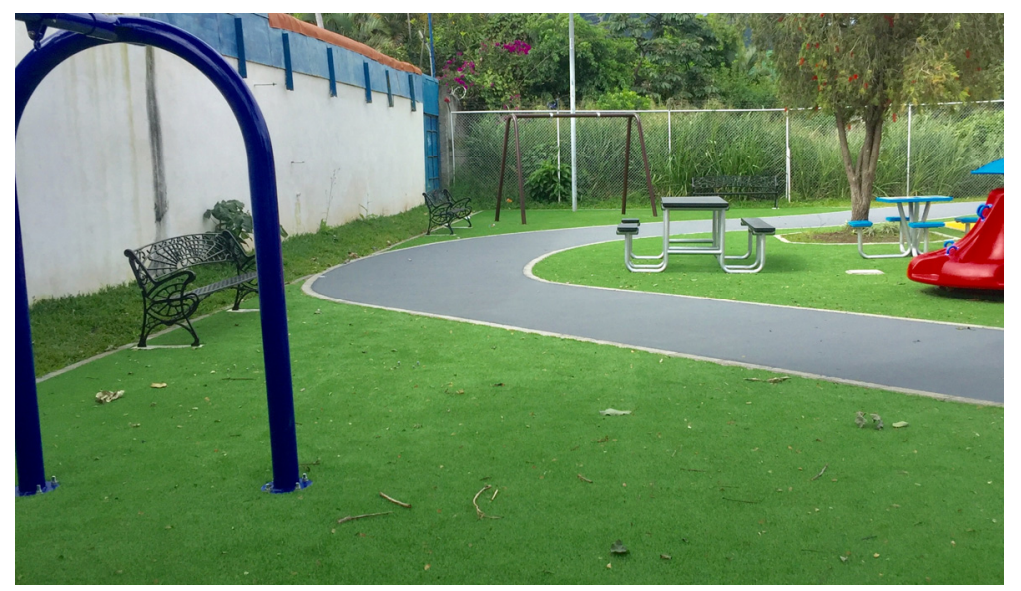

Figure 1: Cocori Park in Costa Rica. Replacing nature with synthetic grass. 
Consequently, the abandonment of flora and fauna as dwellers in architecture has to be put into question when it is known that humans cannot be the only inhabitants of ecosystems without seriously damaging them. Vegetation needs new places to live in the urban environment and, at the same time, humans need to reconnect with nature.

\subsection{The Inhabitants' triangle}

The aforementioned statement brings us to the next task at hand; the new tenants in architecture. The new tenants, understanding the word "tenant" to be an organism that has the right to occupy and use a property for rent, will be the flora and fauna; the human being will have new roommates.

When discussing the role of biodiversity in an architectural project, one cannot avoid taking into account the economic impact that these new inhabitants will have on any project. The use of the word "tenant", in this paper, to refer to flora and fauna as dwellers in architecture comes from the idea that apart from being inhabitants, they are also tenants; that is, they pay rent. Although it's true that one of the biggest challenges for policymakers, and economic development practitioners, has been how to shape a strong economic argument for nature's contribution to society [7], and that trying to evaluate the economic appraisal of the new tenants presents some difficulty because it is believed that nature's form of payment does not generate direct monetary remuneration - as a human tenant would - there is a growing body of research that suggests that the access to biodiversity and green spaces are valuable to individuals, businesses and communities [8]; value translatable to positive externalities in consumption and direct and indirect economic benefits.

As said before, while the new tenants may not generate a direct monetary remuneration, they do have their own currency in which they can pay their rent; they pay with oxygen, ability to absorb dust, like an anti-noise machine that produces silence, eliminating toxins, purifying contaminated rainwater, as a producer of happiness and health, as a carrier of butterflies, pollinators and beauty, and in many other currencies [9]. In this way, just as symbiotic relationships occur in nature, where two different organisms living in close physical association benefit from each other, human beings can benefit from the currencies that nature has to offer in exchange for dwelling spaces within an urban environment.

This new coexistence brings with it a certain network of contextual causes and effects in the affairs of a project. To illustrate, take one of Jan Gehl's ideas of architecture [10], where: "Architecture is not form, but the interactions between life and form, and only if life and form interact in a good and successful way then it will be good architecture". From the previous statement we could emphasize the importance of the interactions between life and form in architecture, and if we add to this the idea that the human being is only one of the many presences on the planet, then it means that there are other living beings, like: the flora and fauna, interacting with architecture (Fig. 2). This means that there exist three different protagonists who inhabit architecture: flora, fauna and the human being.

Next, the three protagonists, established previously, are placed in the corners of a triangle and, in this case, a central protagonist is added: architecture, as a mediator between the three actors. In the inhabitant's triangle it is not only convenient to know something about the protagonists, but also to know about how they affect themselves and each other; thus, lines are drawn representing the possible impacts between and within themselves (Fig. 3), thereby diagramming the essential messages and impacts of the tenants' interactions on the project.

In order to delineate the theme to be treated in this paper, and to be able to further explore the task at hand, to a certain extent, regarding the quality of life of the human being, the 


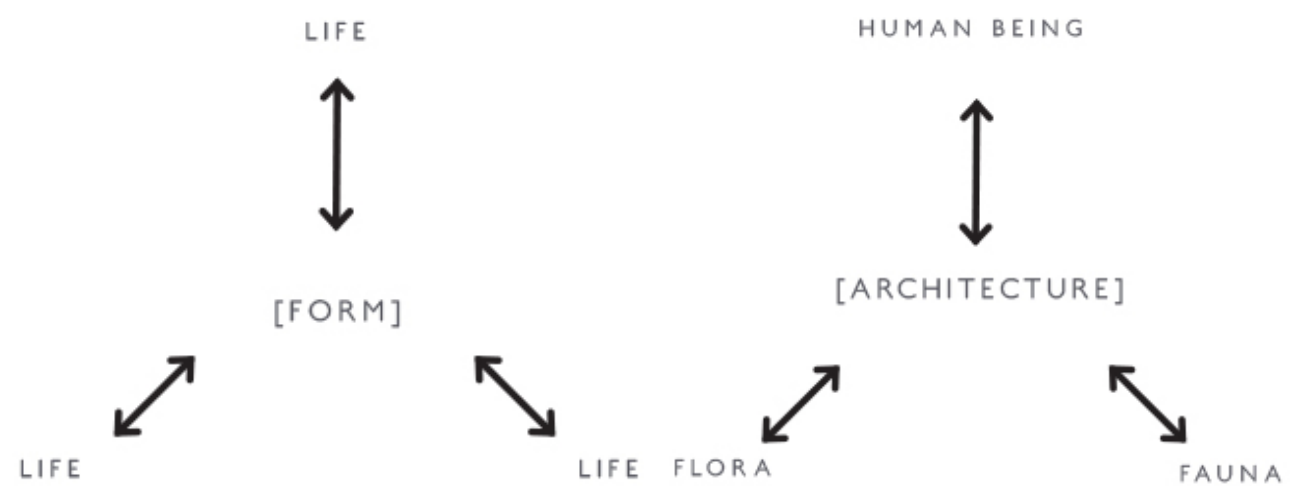

Figure 2: Relation between life-form and other life forms in architecture.

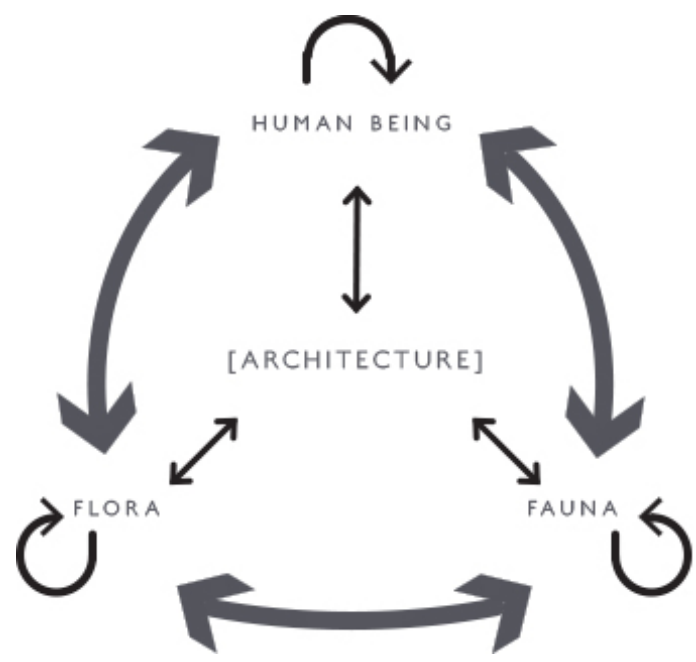

Figure 3: The inhabitants triangle.

theme to be treated will be the relationship: flora-human being. This is done in order to define the research scope and not to extend in the complexity that would be required to analyze each and every single one of the messages that all the protagonists could transmit between them and to themselves.

\section{QUALITY OF LIFE IN THE RELATIONSHIP: FLORA-HUMAN BEING}

In order to understand why vegetation deserves to take a leading role in architecture, or rather, to take back its leading role, it is necessary to understand the relationship between flora and human beings, together with the implications in the physiological and psychological aspects that this symbiosis entails in the quality of life of human beings. The quality of life is a polysemic and dynamic concept, in relation to the time in which it is analyzed, as well as limited by the particular perspective of the areas from which it is approached [11].

For example, in one of civilization's earliest efforts to bring nature to the city and to improve the quality of life, Cyrus the Great intuitively built lush green gardens in the busy 
urban capital of Persia 2,500 years ago to increase human health and promote a sense of "calm" in an overpopulated city [12].

Returning to the Hanging Gardens of Babylon, Josephus, an Israelite historian born in $37 / 38$ CE, a contemporary of the Roman Emperor Nero, wrote a brief passage on the Hanging Gardens of Babylon [13]; Josephus' writings explain why the Hanging Gardens were created [14]: "[...] In this palace (Nebuchadnezzar II), built and organized the so-called Hanging Garden by creating high stone terraces that made it look very similar to the mountains planted with all kinds of trees. He did this because his wife, who had grown up in Media, longed for a mountainous environment".

The king's wife's desire to return to her homeland could be explained with the help of the hypothesis presented in the 1960s by psychologist and philosopher Erich Fromm: biophilia. This concept was popularized (and slightly modified) in 1984 by the entomologist Edward O. Wilson, who later, together with the ecologist Stephen Kellert, as cited by Byrne [15], would provoke an efflorescence of research on the subject.

The biophilia hypothesis proclaims a human dependence on nature that extends far beyond simple problems of physical and material sustenance, to also embrace the human desire for aesthetic, intellectual, cognitive and even spiritual satisfaction [16].

Humans (from the primate subset to our current form) have lived over $99.99 \%$ - of the last six or seven million years - in a natural environment [17]. If we consider the Industrial Revolution as the beginning of urbanization; data shows that less than $0.01 \%$ in the history of the human species have lived in a modern environment, so it is not surprising that some humans yearn to return to where their physiological and psychological functions began [18]. However, this apparent innate tendency to relate to the natural environment has become blurred during the urbanization process and has been replaced by a highly artificial environment [17].

The concept of urbanity was developed within the logic of accumulation articulated and energized, to a great extent, by the culture of the media; therefore, growth in these terms was admitted as a social and economic ideal, understanding that quality of life was the result of the possibilities of consumption and accumulation [11]. This idea alienates flora and fauna as the main providers of mental health and quality of human life, replaced by an artificial environment that has come to represent the new ideal human comfort.

Despite the above, our bodies are better adapted to living in a natural environment [17] since the physiological functions of human beings are made for the forest [19]. This is one of the reasons why humans can relax in a forest environment [17]. Living in a highly urbanized and artificial environment has implications for the physiological and psychological states of humans.

Several studies have shown the influence of the natural environment on human performance, physical activities, mental operations, and psychological and physiological effects [18], [20]-[25]. It is widely believed that coming into contact with nature is somehow beneficial to human health [16]. Current scientific discoveries are illuminating what humans intuitively know: nature has great benefits for the human brain and this is demonstrated through increased happiness, health, and cognition [12].

For Kellert and Calabrese biophilic design represents an opportunity to reconnect with nature as well as an occasion to supply the innate human need to relate to it, and he defines it as an application of different design strategies referred to as experiences and attributes [2].

The most important quality about biophilic design is that it should never be disconnected from context, but rather in a way that the various applications reinforce each other and complement each other, resulting in an integrated ecological whole. To this end, Kellert 
proposes three types of nature experiences within the framework of biophilic design: (i) direct experience, (ii) indirect experience, and (iii) experience of space and place.

"Direct experience" refers to actual contact with the environment; the characteristics of this experience in a built environment should include: natural light, air, plants, animals, water and landscape. On the other hand, "indirect experience" refers to contact with a representation or image of nature, the transformation of its original condition or exposure to patterns of the natural world. Finally, the "experience of space and place" refers to the represented spatial qualities of the natural environment; examples include perspective and refuge, organized complexity, mobility and the search for form, among other aspects [2].

From the biophilic design proposed by Kellert, it is evident that different degrees of connection with nature have different effects on human beings, whereby, for example, it is not the same to see an image of nature (such as a painting or photograph) as to see a tree or a plant in person or even to immerse oneself in a natural environment, surrounded by vegetation. It is clear that the slightest impression or contact with nature has favourable effects on human beings; however, certain approaches to nature have more benefits than others.

\section{TYPOLOGICAL PROPOSAL: SYMBIOTIC SPACE}

While it is true that any use of vegetation in a project - even minimal use - represents a positive impact on the designs, it would not be out of place to look for architectural typologies that enhance biodiversity in the execution of a plan, in such a way that the quality of life of human tenants is improved at the building scale. Therefore, the use of what this author calls the "Symbiotic Space" is proposed.

First of all, it is pertinent to bear in mind the meaning of "symbiont" from its etymological character where it implies a "being" that is in a relationship of symbiosis; symbiosis - a term used by biology - comes from the Greek syn meaning "together" and biosis that refers to the connotation of "living", that is, "living together".

The main theme of the Symbiotic Space is biodiversity and quality of life, therefore: the use of vegetation, human perception in relation to nature, and the reconnection of architecture with the natural environment, are essential in the design of the Symbiotic Space, which is composed of three fundamental concepts that are integrated and interrelated: (i) threshold, (ii) biophilia, and (iii) vegetation.

\subsection{The threshold as a meeting point for the new and old tenants}

In order to delve in the Symbiotic Space, we must remember what was said before about the "hermetic sealing" (this strong division between the interior and the exterior). For this, the use of thresholds is proposed in order to blur this partition and increase the connection and interrelation between species.

The human being has the ability to separate spaces, that is, to establish a limit between them. In the language of architecture, a limit is a spatial delimiter. The architectural boundary is generally understood as a partition of material: a floor, wall, or ceiling that separates adjacent spaces. The transition from one space to another is a problem that, in principle, must be solved by design, and the threshold, being a transition zone, thrives on the ambiguity of opening or closing spaces.

If we take into consideration that thresholds are spatial conditions that create openings in the limits and allow movement and transition in space, then they have the potential to function as a possible conciliatory tool for the relationships between flora, fauna and human beings in architecture. These openings in spatial boundaries can generate spatial transitions that 
generate a heterogeneous microclimate, which could benefit the purpose of the integration of the species in the architecture.

This threshold should not be confused with the approach to designing entrances and portals, but instead be understood as ways of addressing edges, surfaces, and transition spaces within architecture.

If we define a threshold as a contact area for living [26], an interface between action spaces and retreat areas that allow for the inclusion of a social aspect and facilitate "contact", it could be said, then, that through the threshold the human being can interact with the "other" tenants: the flora and fauna, in a controlled way and without sacrificing the human beings' personal space. According to Hertzberger [27], the threshold constitutes the spatial condition for the meeting and dialogue between areas of different orders.

The threshold is decisive in the Symbiotic Space because of the inherent "quality" it presents as a spatial pathway - being a transition space between other larger spaces - the threshold can be: a corridor, a balcony, an entrance, etc. This being the case, it must be necessary to cross the threshold in order to reach the desired destination. The Symbiotic Space, in this way, through the threshold, presents a process of spatial perception that allows the human tenant to "submerge" in the natural environment and, while making its journey, cohabit for a moment with the other tenants. This offers - in addition to converting this site into a dynamic space - the necessary tools for human beings to interact with nature, in what biophilia would define as a direct and submerged experience with nature.

\subsection{Biophilia and vegetation}

The threshold is a space that gives the opportunity for the vegetation to grow freely, as it would do in a natural environment, it provides the architectural tools (as green roofs do), to offer a spatial experience to the human being; due to the nature of the space, the human tenant will inevitably have to go through the Symbiotic Space, in a controlled and planned way, to reach its destination. A controlled and planned way of interaction between the different species is needed, as it gives the human tenant the opportunity to decide the level of reciprocity at the new meeting points between the different tenants.

In this way it is necessary to keep in mind that the benefits of contact with nature depend on repeated experience, where people may possess an inclination to affiliate with nature, but that inherent tendency to affiliate with nature must be cultivated and developed in order to be functional. It is for this reason that the Symbiotic Space can function as a conciliatory tool between the different inhabitants, as these are spaces that the human being habitually travels through.

Although it is true that the direct experience of biophilic design is a fundamental part in the use of the Symbiotic Space at the threshold, it is equally important that the vegetation grows naturally and in all its splendour. This is because the quality of life is not the only problem; consequently, biodiversity is a fundamental point in the Symbiotic Space.

If only the concepts of threshold and biophilia are used in the Symbiotic Space, then the vegetation could be ornamental, to such an extent that one could simply use images of the vegetation or even artificial vegetation or synthetic grass, since in this way one would fulfil the role that the image of nature plays on the human being; that is to say, with the use of images or ornamental vegetation, although it is not the same as a direct experience, it is certain that it fulfils the expectation of improving the quality of life of the human being in the space he lives in, according to the biophilia. However, it would not fulfil one of the fundamental objectives of the Symbiotic Space: to promote biodiversity. 


\subsection{Design principles}

The Symbiotic Space is supported by tools such as green roofs to be inserted in the thresholds of the buildings, supported by structures or footbridges and permeable materials that allow the transit of the human being. It offers a conceptual as well as practical solution to the growing crisis of biodiversity and quality of life by providing the means to intervene in the buildings through the insertion of biodiversity injections.

The Symbiotic Space acknowledges the fact that human beings need to feel protected and at ease when dwelling in architecture, and thus its main objective is to find new ways in which vegetation can inhabit architecture without necessarily "sacrificing" conventional human dwelling spaces, such as the bedroom, where the space can be completely "sealed off" and, in this way, protect the tenant from the outside dangers. Instead, this proposal aims to take into account both the human being and the vegetation within the design process of dwelling spaces within an architectural project.

It is convenient, in this case, to lean on an existing space that can meet the qualities of the Symbiotic Space, in order to better understand how this space can be seen and how the design criteria that compose it works, which is why this paper uses an image of the Plaza in Véritas University, located in San José, Costa Rica (Fig. 4).

In order to fulfil this purpose, the proposal is governed by the following criteria: limit, programme, experience, spatial pathway and vegetation (Fig. 5).

\subsubsection{Spatial limit}

The Symbiotic space, as a conciliatory tool between the natural and artificial environment, shall have at least one of its sides in contact with an interior space and the other with an exterior space. This, to guarantee natural lighting and ventilation Furthermore, it cannot have a clear boundary between the spaces it connects.

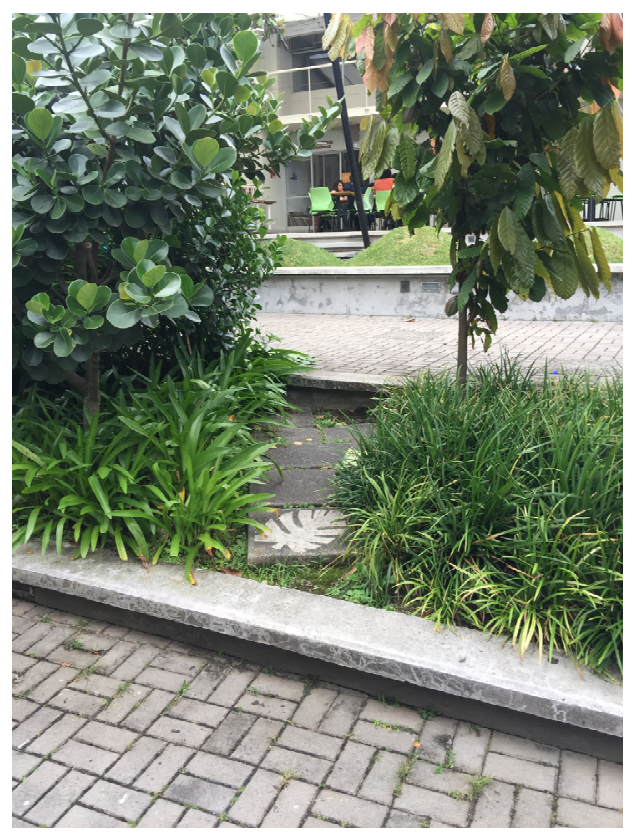

Figure 4: A Symbiotic Space. 

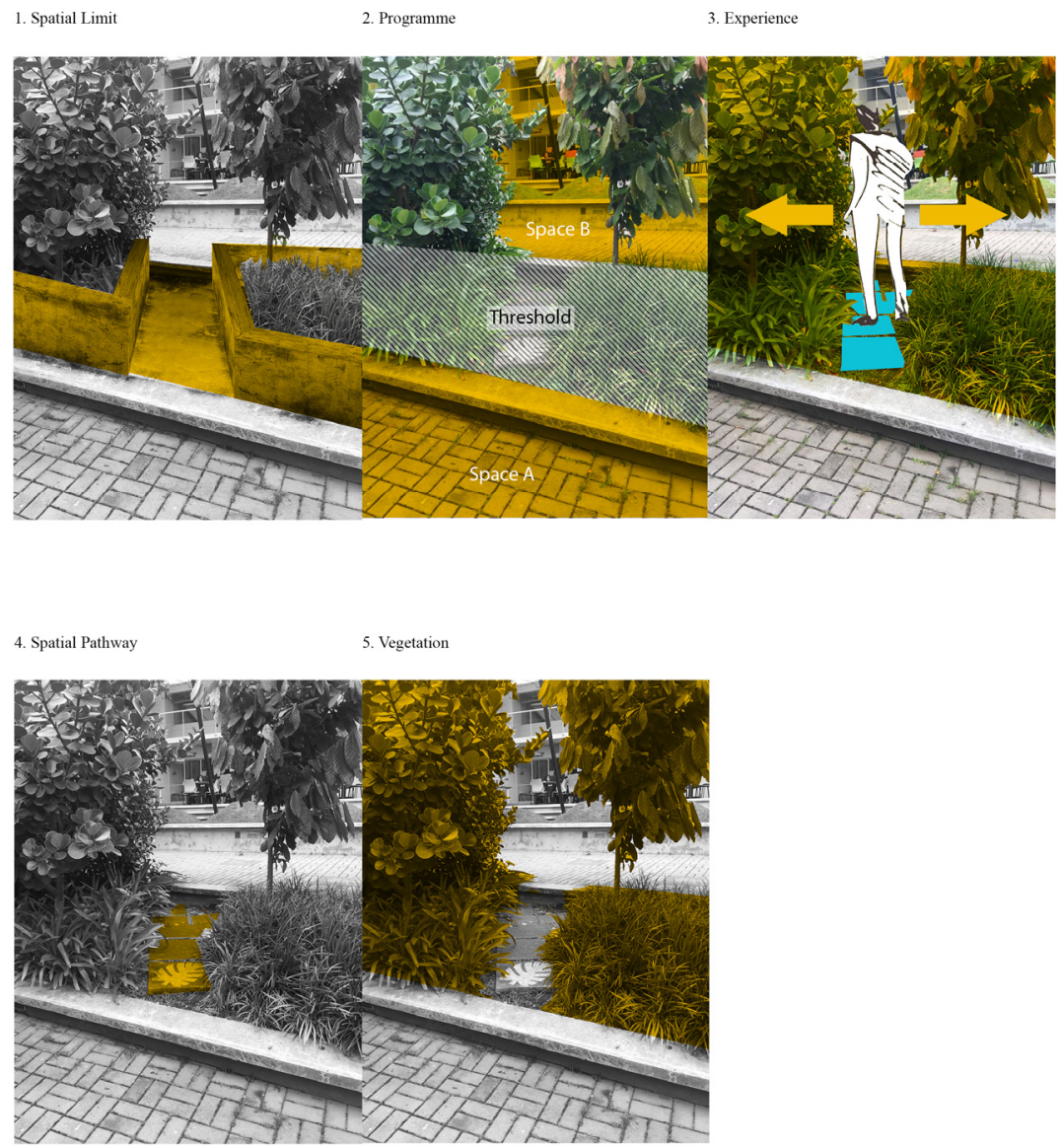

Figure 5: Design principles.

\subsubsection{Programme}

The space is located on thresholds, whether they are: corridors, entrances, balconies, etc. The Symbiotic Space stops being a Symbiote when it exceeds the spaces it connects or when it becomes a space in itself. In other words, the essence of the Symbiotic Space is to be a place of transition between two other spaces.

\subsubsection{Experience}

The Symbiotic Space must promote a direct experience with nature by relying on the use of the vegetation in the space. Also, it must promote an indirect experience that, by either using organic materials or images, strengthens the notion of nature in space and, finally, it must promote the experience of space and place through pathways.

\subsubsection{Spatial pathway}

The Symbiotic Space must have a path, either permeable or natural, that allows the human tenant to go through, and in this way, allow contact with nature, and thus experience the benefits of biophilia. 


\subsubsection{Vegetation}

The Symbiotic Space does not establish a fixed correspondence between the number of plant tenants in relation to the number of human tenants. Part of the idea of this typology is that any use of vegetation, even the minimum, has benefits in the project. Nevertheless, the Symbiote Space urges to let the vegetation to grow freely, as it would in a natural environment.

\section{CONCLUSION}

The subject of study presented in this paper requires further development, nevertheless, although architecture, throughout history, has adapted to solve the relevant problems of its time, it has also long ignored very important issues such as biodiversity and quality of life in relation to contact with nature.

In the contemporary context, the discussion must demand from architecture, beyond beauty and protection, coexistence and quality of life. It is time to recognize vegetation as that complex being that it is, and it is the duty of architecture to start designing according to its needs and not as a last-minute idea, or as a spontaneous element that grew in a residual space.

Architecture must make society, this includes the plant and animal tenants within the human and architectural context; therefore, it is urgent that architecture speaks about these issues.

\section{REFERENCES}

[1] Beatley, T., Biophilic Cities: Integrating Nature into Urban Design and Planning, Island Press: Washington, DC, pp. 4-15, 2011.

[2] Kellert, S. \& Calabrese, E., The Practice of Biophilic Design. www.biophilicdesign.com. Accessed on: 21 Oct. 2019.

[3] Boeri, S., A Vertical Forest, Corraini Edizioni: Italy, 97 pp., 2015.

[4] Cartwright, M., Hanging Gardens of Babylon. Ancient History Encyclopedia. www.ancient.eu/Hanging_Gardens_of_Babylon/. Accessed on: 24 Sep. 2019.

[5] Hensel, M., Performance-oriented architecture: An integrated discourse and theoretical framework for architectural design and sustainability towards non-discrete and nonanthropocentric architecture. PhD dissertation, University of Reading, 156 pp., 2012.

[6] Editorial \& Jiménez, Q., Biodiversidad en la ciudad costarricense. Ambientico, 232233, pp. 2-8, 2013.

[7] National Economy Northwest, The Economic Value of Green Infrastructure, United Kingdom, 4 pp., 2008.

[8] UK Green Building Council, Biodiversity and the Built Environment, London, 5 pp., 2009.

[9] Hundertwasser, F., For a More Human Architecture in Harmony with Nature, Köln: Taschen, pp. 63-64, 2018.

[10] Youtube, Jan Gehl Interview: How to Build a Good City. www.youtube.com/ watch? $\mathrm{v}=9$ x5Hor2MP8. Accessed on: 6 Aug. 2018.

[11] Baldi, G. \& García, E., Calidad de vida y medio ambiente. La psicología ambiental. Universidades, 30, pp. 9-16, 2005. www.redalyc.org/pdf/373/37303003.pdf. Accessed on: 21 May 2018.

[12] Williams, F., This is your Brain on Nature. Nat. Geogr., 229 pp., 2016.

[13] Dalley, S., The Mystery of the Hanging Garden of Babylon, Oxford University Press: Oxford, pp. 34-35, 2015.

[14] Burstein, S., The Babyloniaca of Berossus, Undena Publications: Malibu, 27 pp., 1978. 
[15] Byrne, J., Biophilia, p. 1, 2010. DOI: 10.1145/1179849.1179879.

[16] Kellert, S.R. \& Wilson, E.O., The Biophilia Hypothesis, Island Press: Washington, DC, 73 pp., 1993.

[17] Park, B.J., Tsunetsugu, Y., Kasetani, T., Morikawa, T., Kagawa, T. \& Miyazaki, Y., Physiological effects of forest recreation in a young conifer forest in Hinokage Town, Japan. Silva Fennica, 43(2), pp. 291-301, 2009.

[18] Hansen, M., Jones, R. \& Tocchini, K., Shinrin-yoku (forest bathing) and nature therapy: A state-of-the-art review. Int. J. Environ. Res. Public Health, 14(8), p. 851, 2017. DOI: https://doi.org/10.3390/ijerph14080851.

[19] Park, B.J. et al., Physiological effects of Shinrin-yoku (taking in the atmosphere of the forest): Using salivary cortisol and cerebral activity as indicators. Proceedings of the 8th International Congress of Psychological Anthropology, pp. 123-128, 2006.

[20] Lohr, V., Pearson-Mims, C. \& Goodwin, G., Interior plants may improve worker productivity and reduce stress in a windowless environment. Environ. Hort., 1995.

[21] Ulrich, R.S., Simons, R.F., Losito, B.D., Fiorito, E., Miles, M.A. \& Zelson, M., Stress recovery during exposure to natural and urban environments. J. Environ. Psychol., 11, pp. 201-230, 1991. DOI: 10.1016/S0272-4944(05)80184-7.

[22] Ulrich, R.S., View through a window may influence recovery from surgery. Science, 224, pp. 420-421, 1984. DOI: 10.1126/science.6143402.

[23] Kaplan, R. \& Kaplan, S., The Experience of Nature: A Psychological Perspective, Cambridge University Press: Cambridge, pp. 177-200, 1989.

[24] Kaplan, S., The restorative benefits of nature: Toward an integrative framework. $J$. Environ. Psychol., 15, pp. 169-182, 1995. DOI: 10.1016/0272-4944(95)90001-2.

[25] Wilson, E.O., Biophilia, Harvard University Press: Cambridge, MA, 1984.

[26] Behnke-Pfuhl, S., Schwellenräume in Haus und Wohnumfeld, Hanover, 26 pp., 2005.

[27] Hertzberger, H., Space and Learning: Lessons in Architecture 3, 010 Publishers: Rotterdam, 49 pp., 2008. 